\title{
Evaluation of seismo-electric anomalies using magnetic data in Taiwan
}

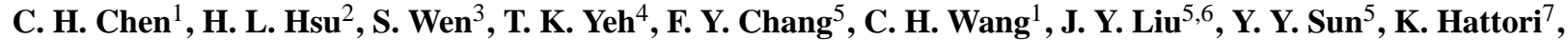 \\ H. Y. Yen ${ }^{2}$, and P. Han $^{7}$ \\ ${ }^{1}$ Institute of Earth Sciences, Academia Sinica, Taipei 115, Taiwan \\ ${ }^{2}$ Institute of Geophysics, National Central University, Jhongli 320, Taiwan \\ ${ }^{3}$ National Center for Research on Earthquake Engineering, Taipei 106, Taiwan \\ ${ }^{4}$ Department of Real Estate and Built Environment, National Taipei University, New Taipei City 237, Taiwan \\ ${ }^{5}$ Institute of Space Science, National Central University, Jhongli 320, Taiwan \\ ${ }^{6}$ Center for Space and Remote Sensing Research, National Central University, Jhongli 320, Taiwan \\ ${ }^{7}$ Graduate School of Science, Chiba University, Inage, Chiba 263-8522, Japan
}

Correspondence to: C. H. Chen (nononochchen@gmail.com)

Received: 20 July 2012 - Published in Nat. Hazards Earth Syst. Sci. Discuss.: -

Revised: 27 November 2012 - Accepted: 29 January 2013 - Published: 7 March 2013

\begin{abstract}
The Parkinson vectors derived from 3-component geomagnetic data via the magnetic transfer function are discussed with respect to epicentre locations and hypocentre depths of 16 earthquakes $(M \geq 5.5)$ in Taiwan during a period of 2002-2005. To find out whether electric conductivity changes would happen particularly in the seismoactive depth ranges, i.e. in the vicinity of the earthquake foci, the frequency dependent penetration depth of the electromagnetic waves (skin effect) is taken into account. The background distributions involving the general conductivity structure and the coast effect at 20 particular depths are constructed using the Parkinson vectors during the entire study period. The background distributions are subtracted from the timevarying monitor distributions, which are computed using the Parkinson vectors within the 15 -day moving window, to remove responses of the coast effect and underlying conductivity structure. Anomalous depth sections are identified by deviating distributions and agree with the hypocentre depths of 15 thrust and/or strike-slip earthquakes with only one exception of a normal fault event.
\end{abstract}

\section{Introduction}

Recognition of anomalous pre-earthquake phenomena has been reported for major earthquakes since 1990 (Fraser-Smith et al., 1990; Bernardi et al., 1991; Molchanov et al., 1992; Kopytenko et al., 1993; Lin and Zeng, 1992; Hayakawa et al., 1996, 1999, 2000; Kawate et al., 1998; Gotoh et al., 2002; Hattori et al., 2002, 2004a, b; Hattori, 2004; Liu et al., 2006; Molchanov and Hayakawa, 2008; Chen et al., 2009, 2010, 2011, 2012; Han et al., 2011; Wen et al., 2012). These reports indicate that geomagnetic anomalies prior to earthquakes are caused by either momentary existence of earthquake-related high conductivity materials or the movement of electric current along faults (Zeng et al., 1995; Merzer and Klemperer, 1997; Yen et al., 2004). Taiwan is located on the western margin of the circum-Pacific seismic zone (Ho, 1988). The convergence of the Philippine Sea plate and the Eurasian plate forms the Manila and Ryukyu trenches and produces many thrust earthquakes (Fig. 1). A 3-component fluxgate magnetometer (the CCU station, $120.47^{\circ} \mathrm{E}, 23.56^{\circ} \mathrm{N}$, Fig. 1) with a $1 \mathrm{~Hz}$ sampling rate was installed in central Taiwan in 2002 (Liu et al., 2006). The data gathered at the CCU station are utilised to investigate subsurface electric and/or magnetic features and to further study the seismo-electromagnetic anomalies in this complex area.

The geomagnetic method is a common technique used to understand and/or monitor changes in the underground conductivity (Chiang et al., 2010) and its susceptibility (Yen et al., 2009) of a specific area. Parkinson (1959) proposed that a linear relationship exists between short-period variations in 


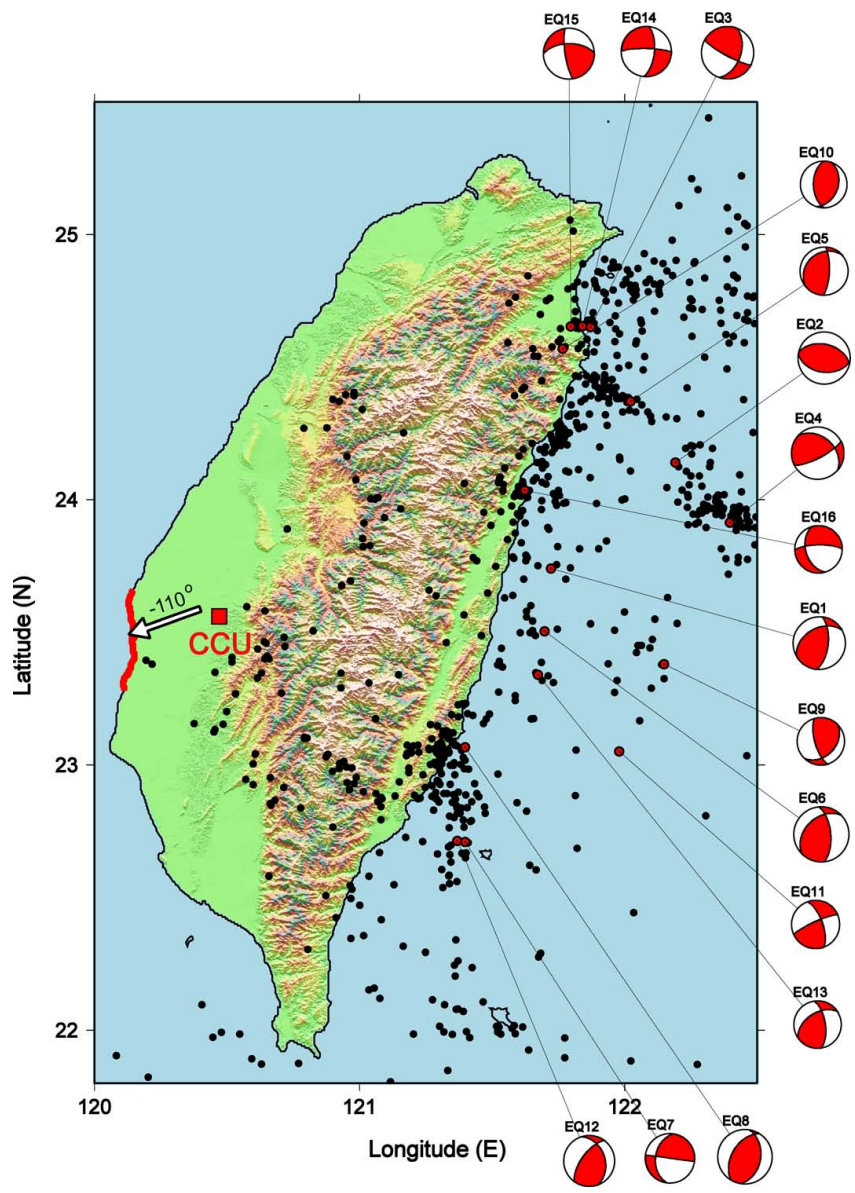

Fig. 1. Locations of epicentres and the CCU station. The black solid circles denote epicentres $(M \geq 4.0)$ from 2002 through 2005. The 16 earthquakes $(M \geq 5.5)$ in this study are represented by red solid circles. Fault plane solutions of earthquakes are shown in the map margin. The red rectangle indicates the CCU station. The red line is the coast line being close to CCU station.

the geomagnetic field, specifically among the vertical component $Z$, the horizontal component $H$ and the declination $D$. The complex and frequency-dependent coefficients $A$ and $B$ are computed from $H, D$ and $Z$ via the magnetic transfer function. $A$ and $B$ are dependent on the underlying electrical conductivity structure (Lilley and Arora, 1982). Induction arrows (i.e. Parkinson vectors) represent the ratios of the real parts of the eastward $B$ to the northward $A$. Induction arrows generally point toward source locations, where the strongest induced vertical variations are generated by the inducing horizontal variations (Parkinson, 1962). The magnitude of an induction arrow is related to both the proximity of the conductor and its conductivity contrast with the background structure (Hitchman et al., 2000). Thus, the magnetic transfer function is usually applied to survey sites where the conductivity is higher than in the nearby areas (Parkinson, 1962; Parkinson and Jones, 1979) and it is widely utilised to study time-varying conductivity due to earthquakes (Zeng et al., 1995) and magnetic coast effects (Ogawa et al., 1986; Armadillo et al., 2001; Hitchman et al., 2000).

In this study, coefficients $A$ and $B$ in 20 different frequency bands are computed from the nocturnal data (20:0004:00 LT) using a moving window with one-minute step. Note that the total number for each coefficient (either $A$ or $B$ ) in one frequency band is 480 each day. The Parkinson vectors at the 20 particular depths (from 5 to $100 \mathrm{~km}$ with a $5-\mathrm{km}$ interval) are derived from frequency-dependent coefficients $A$ and $B$ in different frequency bands through relationships between frequency and depth (i.e. the skin depth; Cheng, 1989; Simpson and Bahr, 2005). The Parkinson vectors are utilised to expose the momentary existence of earthquake-related high conductivity materials associated with 16 earthquakes $(M \geq 5.5$, Table 1; focal mechanisms in Fig. 1) that occurred in Taiwan during the period of 2002-2005. The largest earthquake that occurred during the study period (i.e. EQ2, $M_{\mathrm{L}}=6.8$, on 31 March 2002) is used as a detailed example to illustrate the relationship between seismo-electromagnetic characteristics and earthquake parameters (i.e. hypocentre depths and epicentre azimuths).

\section{Methodology}

The skin depth describes the relationship between the penetration depth and the frequency of electromagnetic waves (Cheng, 1989; Simpson and Bahr, 2005). Because the Earth is a conductor, the skin depth is defined as the penetration distance of a natural electromagnetic wave propagating from the ground surface to the interior of Earth. The skin depth as related to frequency can be written as:

$D_{\text {ep }}=0.503(\rho / f)^{1 / 2}$

where $D_{\text {ep }}$ is depth $(\mathrm{km}), \rho$ is electrical resistivity $(\Omega-\mathrm{m})$ and $f$ is frequency $(\mathrm{Hz})$. The relationship between $\rho$ and $D_{\text {ep }}$ (Fig. 2a) at the CCU station is retrieved from previous magnetotelluric studies conducted nearby (Bertrand et al., 2009; Chiang et al., 2010) and is utilised to compute $f$ in Eq. (1). Thus, $f$ versus $D_{\text {ep }}$ (Fig. 2b) from 5 to $100 \mathrm{~km}$ depth can be used with confidence.

When the relationship between $f$ and $D_{\text {ep }}$ is employed by using the magnetic transfer function, $D_{\text {ep }}$ with respect to the Parkinson vectors can be deduced from the frequencydependent coefficients $A$ and $B$ at $f$. Thus, the azimuth $\left(P_{\mathrm{a}}\left(D_{\mathrm{ep}}\right)\right)$ and magnitude $\left(P_{\mathrm{m}}\left(D_{\mathrm{ep}}\right)\right)$ of the Parkinson vectors at the depth $D_{\text {ep }}$ can be calculated using $B_{\mathrm{r}}(f)$ and $A_{\mathrm{r}}(f)$ as follows:

$$
\begin{aligned}
P_{\mathrm{a}}\left(D_{\mathrm{ep}}\right) & =\arctan \left(B_{\mathrm{r}}(f) / A_{\mathrm{r}}(f)\right) \\
P_{\mathrm{m}}\left(D_{\mathrm{ep}}\right) & =\left(A_{\mathrm{r}}\left(D_{\mathrm{ep}}\right)^{2}+B_{\mathrm{r}}\left(D_{\mathrm{ep}}\right)^{2}\right)^{1 / 2}
\end{aligned}
$$

where $A_{\mathrm{r}}(f)$ and $B_{\mathrm{r}}(f)$ are the real parts of $A$ and $B$, respectively, computed from $Z, H$ and $D$ via band-pass filters centred at frequency $f$. The positive and negative values of 
Table 1. $M \geq 5.5$ earthquake catalogue of Taiwan during the period of 2002-2005 acquired from the broadband array in Taiwan for seismology (BATS; http://bats.earth.sinica.edu.tw/). Relocated data (Engdahl et al., 1998) for the earthquakes were retrieved from the Central Weather Bureau in Taiwan. Since geomagnetic data gaps existed for 6 earthquakes, residuals of 16 earthquakes are utilised. Note that ED and EA denote epicentral distance and epicentre azimuths to the CCU station.

\begin{tabular}{lllllrrrr}
\hline Code & \multicolumn{2}{c}{ Event date and time } & Lat. & Long. & $\begin{array}{r}\text { Depth } \\
(\mathrm{km})\end{array}$ & $M_{\mathrm{L}}$ & EA & ED \\
& & & & & & \\
\hline EQ1 & $2002 / 02 / 12$ & $03: 27: 25.00$ & 23.74 & 121.72 & 29.98 & 6.20 & 81 & 127 \\
EQ2 & $2002 / 03 / 31$ & $06: 52: 49.95$ & 24.14 & 122.19 & 13.81 & 6.80 & 70 & 184 \\
EQ3 & $2002 / 05 / 15$ & $03: 46: 05.91$ & 24.65 & 121.87 & 8.52 & 6.20 & 49 & 185 \\
EQ4 & $2002 / 05 / 28$ & $16: 45: 14.97$ & 23.91 & 122.40 & 15.23 & 6.20 & 79 & 197 \\
& $2002 / 07 / 11$ & $07: 36: 22.57$ & 23.94 & 122.41 & 14.22 & 5.80 & 78 & 199 \\
& $2002 / 08 / 28$ & $17: 05: 34.06$ & 22.26 & 121.37 & 12.03 & 6.00 & 148 & 169 \\
& $2002 / 09 / 01$ & $07: 07: 35.47$ & 23.97 & 122.37 & 15.56 & 5.50 & 77 & 196 \\
EQ5 & $2003 / 06 / 09$ & $01: 52: 50.57$ & 24.37 & 122.02 & 23.22 & 5.70 & 60 & 179 \\
EQ6 & $2003 / 06 / 10$ & $08: 40: 32.05$ & 23.50 & 121.70 & 32.31 & 6.50 & 93 & 123 \\
EQ7 & $2003 / 09 / 10$ & $22: 55: 6.06$ & 22.71 & 121.40 & 85.36 & 5.80 & 135 & 132 \\
EQ8 & $2003 / 12 / 10$ & $04: 38: 13.52$ & 23.07 & 121.40 & 17.73 & 6.40 & 120 & 108 \\
EQ9 & $2004 / 02 / 04$ & $03: 23: 59.42$ & 23.38 & 122.15 & 17.36 & 5.60 & 97 & 169 \\
EQ10 & $2004 / 05 / 09$ & $20: 06: 47.57$ & 24.57 & 121.77 & 69.16 & 5.50 & 49 & 171 \\
EQ11 & $2004 / 05 / 16$ & $06: 04: 08.70$ & 23.05 & 121.98 & 12.85 & 5.70 & 110 & 161 \\
EQ12 & $2004 / 05 / 19$ & $07: 04: 12.94$ & 22.71 & 121.37 & 27.08 & 6.00 & 136 & 129 \\
& $2004 / 11 / 11$ & $02: 16: 44.5$ & 24.31 & 122.16 & 27.26 & 6.10 & 64 & 188 \\
EQ13 & $2005 / 02 / 18$ & $20: 18: 18.83$ & 23.34 & 121.67 & 15.28 & 5.60 & 101 & 123 \\
EQ14 & $2005 / 03 / 05$ & $19: 06: 51.73$ & 24.65 & 121.84 & 6.39 & 5.90 & 49 & 182 \\
EQ15 & $2005 / 03 / 05$ & $19: 08: 00.09$ & 24.65 & 121.80 & 6.95 & 6.00 & 48 & 179 \\
EQ16 & $2005 / 04 / 30$ & $14: 48: 17.23$ & 24.04 & 121.62 & 8.45 & 5.60 & 66 & 127 \\
& $2005 / 06 / 01$ & $16: 20: 05.66$ & 24.64 & 122.07 & 64.78 & 6.00 & 53 & 199 \\
& $2005 / 09 / 06$ & $01: 16: 00.41$ & 23.96 & 122.28 & 16.76 & 6.00 & 76 & 187 \\
\hline
\end{tabular}

$P_{\mathrm{a}}\left(D_{\mathrm{ep}}\right)$ bounded to intervals of $0 \sim 180^{\circ}$ and $0 \sim-180^{\circ}$ are determined in clockwise and anticlockwise directions from north to south, respectively.

When the Parkinson vectors are employed in surveying the momentary existence of earthquake-related high conductivity materials, influences of the coast effect and inhomogeneous conductivity of subsurface structure have to be considered. The coast effect (Parkinson and Jones, 1979; DeLaurier et al., 1983; Parkinson, 1983) is caused by an induction field resulting from differing conductivity properties of sea water, the oceanic and continental lithosphere and has been observed in countries such as Japan (Ogawa et al., 1986), Italy (Armadillo et al., 2001) and Australia (Hitchman et al., 2000). The coast effect causes that the induction arrows point toward the high conductivity sea water and remain simultaneously orthogonal to the nearby coastline. Here, influences of the coast effect and underlying conductivity structure on Parkinson vectors are assumed to be persistent within the 4-yr study period (i.e. from 2002 through 2005). To evaluate these persistent responses, the background distributions in azimuth and magnitude at $D_{\text {ep }}$ are constructed by $P_{\mathrm{a}}\left(D_{\mathrm{ep}}\right)$ and $P_{\mathrm{m}}\left(D_{\mathrm{ep}}\right)$ during the entire period (2002-2005). In contrast, the time-varying distributions in azimuth and magnitude at $D_{\mathrm{ep}}$ are computed by $P_{\mathrm{a}}\left(D_{\mathrm{ep}}\right)$ and $P_{\mathrm{m}}\left(D_{\mathrm{ep}}\right)$

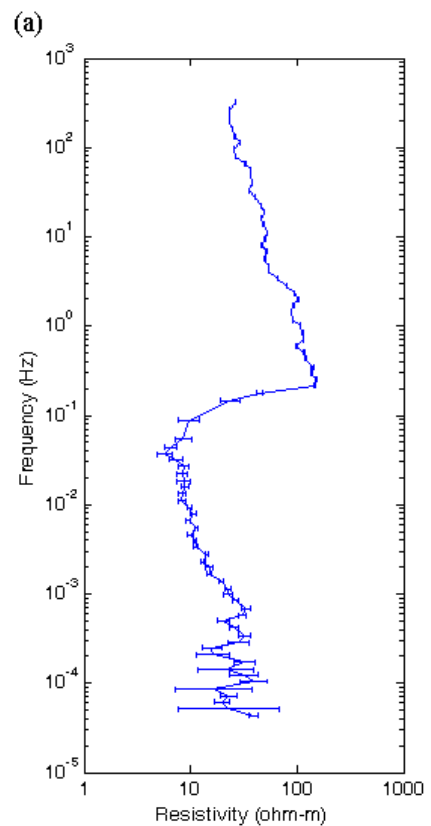

(b)

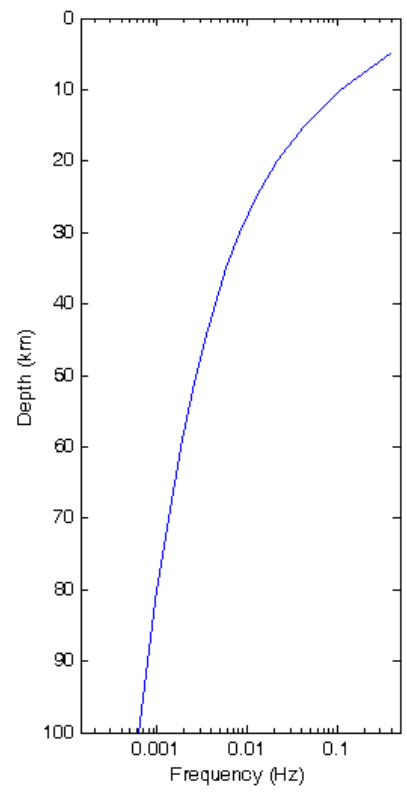

Fig. 2. The apparent resistivity of magnetotelluric data (retrieved from Chiang et al., 2010) close to the CCU station (a) and the depth to frequency section (b). 
within a 15-day moving window to investigate the changes in Parkinson vectors with time.

Anomalous responses at different azimuths are obtained by subtracting the normalised background azimuth distribution from the normalised time-varying one at each studied depth. Derived differences from the normalised background azimuth distribution (i.e. the anomalous azimuth deviations) at 20 particular depths, which may be related to earthquake azimuths at respective hypocentre depths, are used to identify anomalous azimuths. Note that positive anomalous azimuth deviation denotes the existence of high conductivity relative to the background. Furthermore, the persistent effects on magnitude are removed by subtracting the normalised background magnitude distribution from the normalised time-varying one at each studied depth. Derived differences from the normalised background magnitude distribution are summed individually for each of the 20 depths. These 20 summed values versus the related depths are utilised to construct anomalous depth sections. The computed depth of anomalous conductivity is defined by using the largest summed value from these depth sections.

\section{Observation and interpretation}

Figure 3 shows the normalised background azimuth distributions of $P_{\mathrm{a}}\left(D_{\mathrm{ep}}, D_{\mathrm{ep}}\right.$ ranges from 5 to $\left.100 \mathrm{~km}\right)$ to reveal the persistent effect (i.e. influences of the coast effect and underlying conductivity structure). The normalised background distributions of $P_{\mathrm{a}}$ mainly concentrate within a range between $-100^{\circ}$ and $-120^{\circ}$ from shallow to deep depth at the western side of the CCU station. This direction ranges from $-100^{\circ}$ to $-120^{\circ}$ toward sea water and is orthogonal to the strike $\left(169^{\circ}\right)$ of the coast line nearest the CCU station (also see Fig. 1), which agrees with the coast effect. Regarding $P_{\mathrm{a}}$ toward the eastern side of the CCU station, no significant direction can be found from the normalised background distributions of shallow $P_{\mathrm{a}}\left(D_{\mathrm{ep}}, D_{\mathrm{ep}}<30 \mathrm{~km}\right)$. The normalised background distributions of deep $P_{\mathrm{a}}\left(D_{\mathrm{ep}}, D_{\mathrm{ep}}>30 \mathrm{~km}\right)$ orient at a direction of approximately $75^{\circ}$. This suggests that the crustal structure changes at approximately $30 \mathrm{~km}$ depth, thus, indicating the Moho discontinuity in accordance with Wang et al. (2010) at a depth between 30 and $40 \mathrm{~km}$ beneath Taiwan. These results also suggest the existence of relatively high conductivity materials beneath the central mountain range, which is in agreements with the magnetotelluric survey reported by Chiang et al. (2010).

Figure $4 \mathrm{a}$ illustrates the anomalous azimuth deviations of $P_{\mathrm{a}}(15 \mathrm{~km})$ versus the epicentre azimuth $\left(70^{\circ}\right)$ of EQ2 covering a period of 110 days. The anomalous azimuth deviations at each azimuth are comparable and no apparent direction can be observed except for a few days prior and after EQ1, EQ2 and EQ3. The intense and/or positive anomalous azimuth deviations at azimuth of $70^{\circ}$ abruptly appeared and then disappeared 15 days before and after EQ2, respectively.
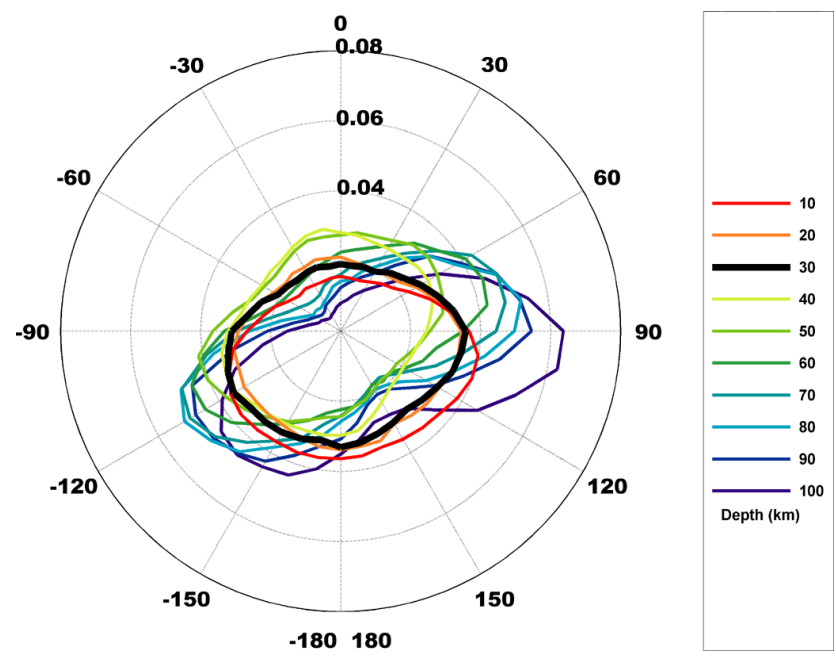

Fig. 3. The background azimuth distribution of $A_{\mathrm{p}}\left(D_{\mathrm{ep}}\right.$, where $D_{\mathrm{ep}}$ ranges from 5 to $100 \mathrm{~km}$ ). The black line denotes $D_{\text {ep }}$ of $30 \mathrm{~km}$ revealing a discontinuous boundary of background azimuth distributions.

These results are consistent with the momentary existence of earthquake-related high conductivity materials observed by Lin and Zeng (1992) with respect to 11 earthquakes in China that occurred between 1976 and 1988. Figure 4b reveals depth sections with time-varying anomalous conductivity over the same time span. The computed depth associated with EQ2 is $10 \mathrm{~km}$, which matches with its reported hypocentre depth $(13.81 \mathrm{~km})$. Figure $4 \mathrm{c}$ displays the Dst index, which characterises the severity of magnetic storms. Discrepancy between the detected anomalies and magnetic storms in the time domain suggests that the anomalous azimuth deviations and depth sections are not related with changes in space weather, but local earthquakes. Notably, anomalous depth sections (Fig. 4b) roughly agree with the actual hypocentre depths of EQ1 and EQ3 because of relatively small differences (16 km between EQ1 and EQ2; $5 \mathrm{~km}$ between EQ3 and EQ2) in their hypocentre depths.

Figure 5 shows the comparison between computed and reported hypocentre depths for the 16 studied earthquakes. The difference between the computed and reported hypocentre depths is generally small $(<20 \mathrm{~km})$ for most earthquakes, except for EQ9, EQ10, EQ11 and EQ16. We checked the entire earthquake catalogue (http://www.cwb.gov.tw) and found that other small seismic events $(M<5.5)$ occurred close to the studied earthquakes at the computed depths. That is, those events were identified instead of EQ9, EQ10 and EQ11. As to the mismatch in the case of EQ16, it may be caused by the fact, that EQ16 is the only event with a normal faulting focal mechanism, whereas the other 15 events are of reverse faulting or strike-slip type. Liu et al. (2006) suggested that seismo-magnetic anomalies are often observed in reversed fault or strike-slip earthquakes because of the discrepancy of earthquake-related stress accumulation. 

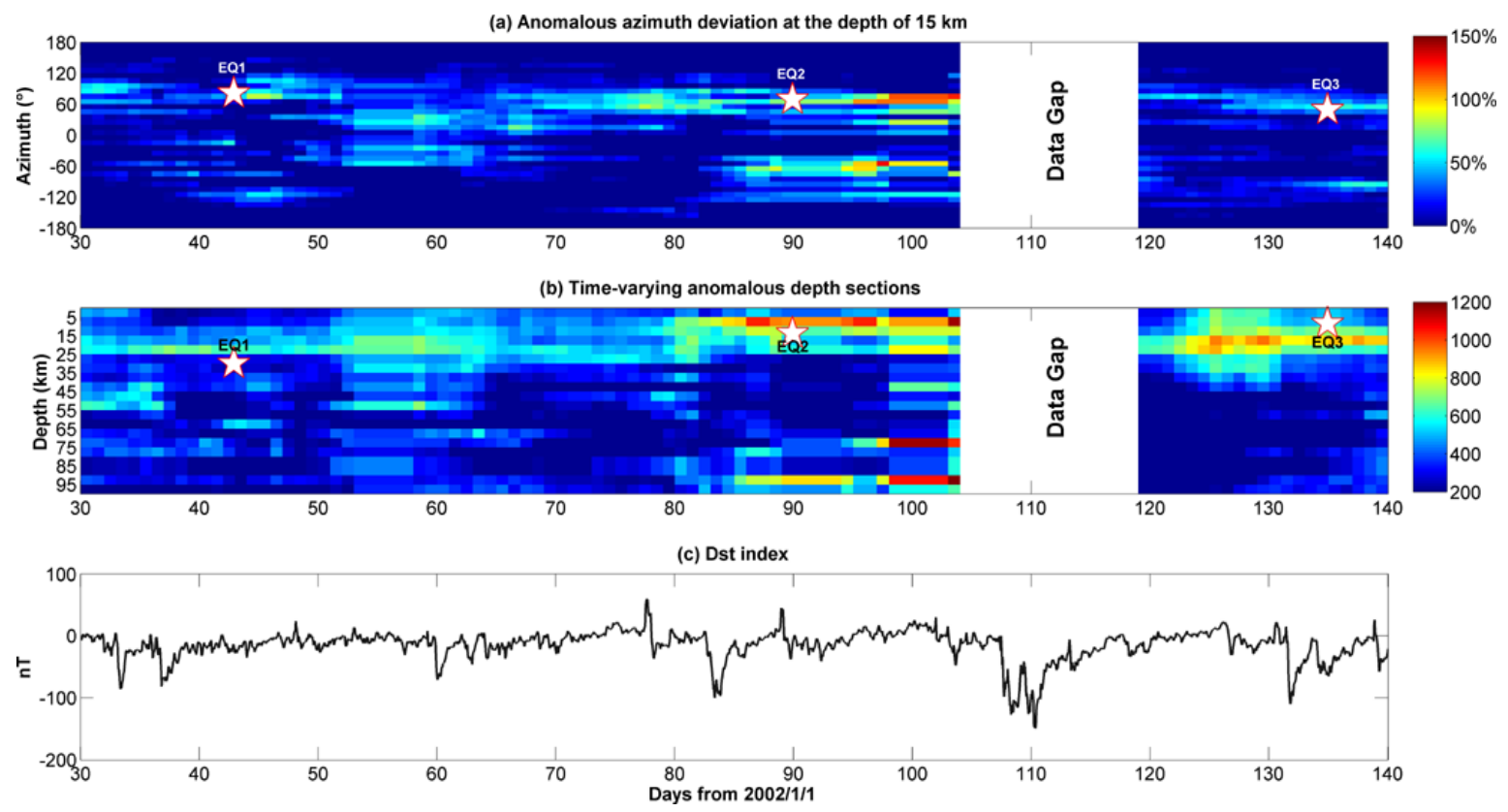

Fig. 4. The anomalous azimuth deviations at $15 \mathrm{~km}$ deep (a), time-varying anomalous depth sections (b) and Dst index (c) during EQ2. Open stars denote the earthquake azimuths and the hypocentre depths of EQ1, EQ2 and EQ3.
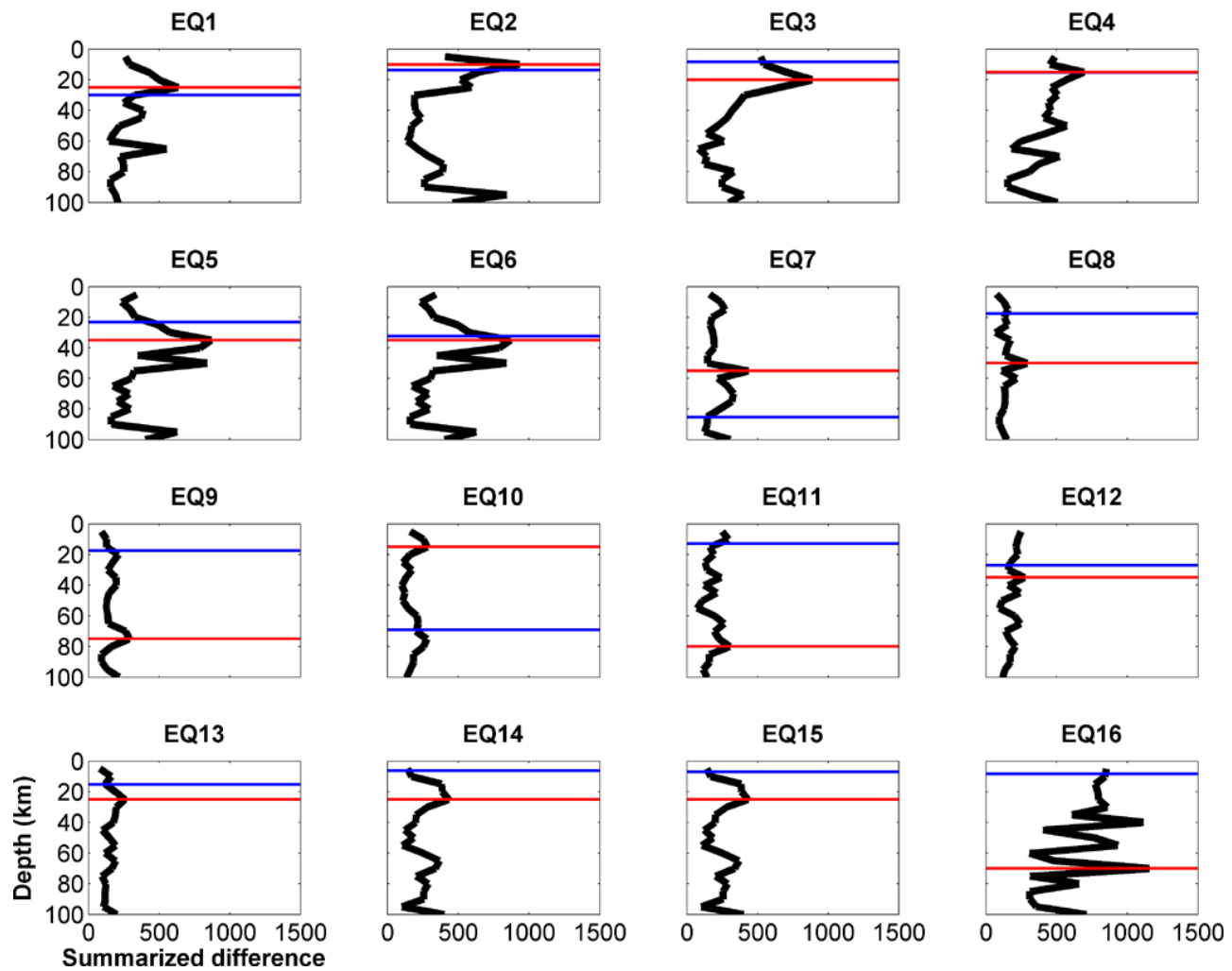

Fig. 5. The computed and reported hypocentre depths of 16 earthquakes. The blue lines denote reported hypocentre depths. The black lines show summarised differences on the depth profile. The red lines are the computed depths determined by the largest summarised differences. 
The relatively large difference between the computed and hypocentre depths in EQ16 is, thus, inferred to be associated with its normal-fault mechanism, and we conclude that the analytical method proposed in this study is more applicable to reverse and strike slip events.

\section{Discussion and conclusions}

Our analytical results indicate that high conductivity materials momentarily exist near the hypocentre during most $(15 / 16)$ studied earthquakes. These features are consistent with the observations using magnetotelluric equipment at locations close to other major earthquakes (Chen and Chen, 2000; Honkura et al., 2000). Rock susceptibilities change with accumulating stress (Stacey, 1962; Nagata, 1970) during the pre-earthquake period. Meanwhile, increases in electric conductivity around epicentres were also observed a few days before earthquakes (Lin and Zeng, 1992; Chen and Chen, 2000). Although the fundamental mechanisms of the conductivity increase are not fully understood, it has been proposed that the electrokinetic (Fenoglio et al., 1995) and microfracturing effects (Molchanov, and Hsayakawa, 1995) may play an essential role in this process. Hattori (2004) and Liu et al. (2006) reported that seismo-electromagnetic anomalies were often observed by magnetometers close to earthquake epicentres. Therefore, we expect that hypocentre locations could be estimated in many cases by using geomagnetic data in particular from high density magnetic station arrays. A shallow hypocentre depth is a common feature of major earthquakes that cause great damage, such as the 1995 Hanshin earthquake (17 January 1995, $M=7.2$, depth $=16 \mathrm{~km}$ ) and the 1999 Chi-Chi earthquake (29 September 1999, $M=7.6$, depth $=8 \mathrm{~km}$ ). Hypocentres are distributed throughout a large depth range of, for example, 5-300 km in some regions such as the subduction zone of the Philippine Sea plate beneath Eurasian plate in northeastern Taiwan (Ho, 1988). Thus, pin-pointing the hypocentre depth before an earthquake is very important, in view of most geophysical measurements being confined on the Earth's surface. Using the magnetic transfer function and accompanying skin depth, this study demonstrated that continuous geomagnetic data can be closely related to hypocentre depths. Our analyses of the magnetic transfer function and frequency dependent skin depths, based on data from 3-component magnetometres and magnetotelluric equipment provided a firm estimation of hypocentre depths. This knowledge may help to better assess the extent of damage that a strong earthquake may cause, in particular, if the analyses indicate a shallow depth for such a strong seismic event. Eventually, suitable precautions against seismic hazards can be taken.

In conclusion, the anomalous azimuth deviations orienting toward the epicentres and computed depths approaching the actual hypocentre depths are two important parameters that can be observed in the thrust and strike-slip earth- quakes in Taiwan from 2002 to 2005 . The results suggest that conductivity increases during earthquakes, specifically at the hypocentre depths. These relationships are useful to our understanding the changes in underlying conductivity as the result of earthquake-related stress disturbance. Currently, an automatic system (http://140.109.80.199/goal) has been established in Taiwan to routinely retrieve the anomalous azimuth deviations and the computed depths from 3component magnetic data via the magnetic transfer function. The retrieved data are constantly compared to earthquake parameters (i.e. epicentres and hypocentre depths); satisfactory and interesting results have been obtained. More stations will be installed to increase the accuracy and to further construct a holistic view of conductivity changes with respect to the seismic activity.

Acknowledgements. The authors appreciate the valuable comments raised by the editor and reviewers to greatly improve the manuscript and wish to express appreciation to the Central Weather Bureau for providing the accurate earthquake catalogue and high quality geomagnetic data. The National Science Council of the Republic of China financially supports this research under Contracts NSC 100-2116-M-001-027-MY3.

Edited by: D. Keefer

Reviewed by: two anonymous referees

\section{References}

Armadillo, E., Bozzol, E., Cerv, V., De Santis, A., Di Mauro, D., Gambettal, M., Meloni, A., Pek, J., and Speranza, F.: Geomagnetic depth sounding in the Northern Apennines (Italy), Earth Plants Space, 53, 385-396, 2001.

Bernardi, A., Fraser-Smith, A. C., McGill, P. R., and Villard Jr., O. G.: ULF magnetic field measurements near the epicenter of the $M_{\mathrm{S}} 7.1$ Loma Prieta earthquake, Phys. Earth Planet. In., 68, 4563, 1991.

Bertrand, E., Unsworth, M., Chiang, C. W., Chen, C. S., Chen, C. C., Wu, F., Türkoğlu, E., Hsu, H. L., and Hill, G.: Magnetotelluric evidence for thick-skinned tectonics in central Taiwan, Geology, 37, 711-714, 2009.

Chen, C. H., Liu, J. Y., Yang, W. H., Yen, H. Y., Hattori, K., Lin, C. R., and Yeh, Y. H.: SMART analysis of geomagnetic data observed in Taiwan, Phys. Chem. Earth., 34, 350-359, doi:10.1016/j.pce.2008.09.002, 2009.

Chen, C. H., Liu, J. Y., Lin, P. Y., Liang, W. T., Yen, H. Y., Hattori, K., and Zeng, X.: Pre-seismic Geomagnetic Anomaly and Earthquake Location, Tectonophysics, 489, 240247, dio:10.1016/j.tecto.2010.04.018, 2010.

Chen, C. H., Wen, S., Liu, J. Y., Yeh, T. K., Wang, C. H., Yen, H. Y., Hattori, K., and Lin, C. R.: Seismomagnetic Signal Comparison using the Morlet Wavelet Method, Disaster Adv., 4, 53-60, 2011.

Chen, C. H., Liu, J. Y., Chang, T. M., Yeh, T. K., Wang, C. H., Wen, S., Yen, H. Y., Hattori, K., Lin, C. R., and Chen, Y. R.: Azimuthal propagation of seismo-magnetic signals emitted from large earthquakes in Taiwan, Ann. Geophys., 55, 63-71, doi:10.4401/ag5326, 2012. 
Chen, C. S. and Chen, C. C.: Magnetotelluric soundings of the source area of the 1999 Chi-Chi earthquake in Taiwan: evidence of fluids at the hypocentre, Terr. Atmos. Ocean Sci., 11, 679-688, 2000 , http://www.ocean-sci.net/11/679/2000/.

Cheng, D. K.: Field and Wave Electromagnetic, 2nd Edn., AddisonWesley Pub Comp, 703 pp., 1989.

Chiang, C. W., Chen, C. C., Unsworth, M., Bertrand, E., Chen, C. S., Kieu, T. D., and Hsu, H. L.: The Deep Electrical Structure of Southern Taiwan and Its Tectonic Implications, Terr. Atmos. Ocean Sci., 21, 879-895, 2010, http://www.ocean-sci.net/21/879/2010/.

DeLaurier, J. M., Auld, D. R., and Law, L. L.: The geomagnetic response across the continental margin off Vancouver Island: Comparison of result from numerical modeling and field data, J. Geomagn. Geoelectr., 35, 517-528, 1983.

Engdahl, E. R., van der Hilst, R., and Buland, R.: Global teleseismic earthquake relocation with improved travel times and procedures for depth determination, B. Seismol. Soc. Am., 88, 722743, 1998.

Fenoglio, M. A., Johnston, M. J. S., and Byerlee, J. D.: Magnetic and electric fields associated with changes in high pore pressure in fault zones: Application to the Loma Prieta ULF emissions, J. Geophys. Res., 100, 12951-12958, 1995.

Fraser-Smith, A. C., Bernardi, A., McGill, P. R., Ladd, M. E., Helliwell, R. A., and Villard Jr., O. G.: Low-frequency magnetic field measurements near the epicenter of the $\mathrm{M}_{\mathrm{S}} 7.1$ Loma Prieta earthquake, Geophys. Res. Lett., 17, 1465-1468, 1990.

Gotoh, K., Akinaga, Y., Hayakawa M., and Hattori, K.: Principal component analysis of ULF geomagnetic data for Izu islands earthquakes in July 2000, J. Atmos. Electr., 22, 1-12, 2002.

Han, P., Hattori, K., Huang, Q., Hirano, T., Ishiguro, Y., Yoshino, C., and Febriani, F.: Evaluation of ULF electromagnetic phenomena associated with the 2000 Izu Islands earthquake swarm by wavelet transform analysis, Nat. Hazards Earth Syst. Sci., 11, 965-970, doi:10.5194/nhess-11-965-2011, 2011.

Hattori, K.: ULF geomagnetic changes associated with large earthquakes, Terr. Atmos. Ocean. Sci., 15, 329-360, 2004.

Hattori, K., Akinaga, Y., Hayakawa, M., Yumoto, K., Nagao, T., and Uyeda, S.: ULF magnetic anomaly preceding the 1997 Kagoshima Earthquakes, in: Seismo Electromagnetics: Lithosphere-Atmosphere-Ionosphere coupling, edited by: Hayakawa, M. and Molchanov, O. A., Terra Scientific. Pub. Comp, Tokyo, 477 pp., 2002.

Hattori, K., Takahashi, I., Yoshino, C., Isezaki, N., Iwasaki, H., Harada, M., Kawabata, K., Kopytenko, E., Kopytenko, Y., Maltsev, P., Korepanov, V., Molchanov, O., Hayakawa, M., Noda, Y., Nagao, T., and Uyeda, S.: ULF geomagnetic field measurements in Japan and some recent results associated with Iwateken Nairiku Hokubu Earthquake in 1998, Phys. Chem. Earth., 29, 481-494, 2004a.

Hattori, K., Serita, A., Gotoh, K., Yoshino, C., Harada, M., Isezaki, N., and Hayakawa, M.: ULF geomagnetic anomaly associated with $2000 \mathrm{Izu}$ islands earthquake swarm, Japan, Phys. Chem. Earth., 29, 425-435, 2004b.

Hayakawa, M., Kawate, R., Molchanov, O. A., and Yumoto, K.: Results of ultra-low-frequency magnetic field measurements during the Guam earthquake of 8 August 1993, Geophys. Res. Lett., 23, 241-244, 1996.
Hayakawa, M., Itoh, T., and Smirnova, N.: Fractal analysis of ULF geomagnetic data associated with the Guam earthquake on August 8, 1993, Geophys. Res. Lett., 26, 2797-2800, 1999.

Hayakawa, M., Itoh, T., Hattori, K., and Yumoto, K.: ULF electromagnetic precursors for an earthquake at Biak, Indonesia on February 17, 1996, Geophys. Res. Lett., 27, 1531-1534, 2000.

Hitchman, A. P., Milligan, P. R., Lilly, F. E. M., White, A., and Heinson, G. S.: The total-field geomagnetic coast effect: The CICADA97 line from deep Tasman Sea to inland New South Wales, Explor. Geophys., 31, 52-57, 2000.

Ho, C. S.: An Introduction to the Geology of Taiwan, Central Geological Survey, The Ministry of Economic Affairs, Taipei, 2nd Edn., 192 pp., 1988.

Honkura, Y., Isikara, A. M., Oshiman, N., Ito, A., Ucer, B., Baris, S., Tuncer, M. K., Matsushima, M., Pektas, R., Celik, C., Tank, S. B., Takahashi, F., Nakanishi, M., Yoshimura, R., Ikeda, Y., and Komut, T.: Preliminary results of multidisciplinary observations before, during and after the Kocaeli (Izmit) earthquake in the western part of the North Anatolian Fault Zone, Earth Planets Space, 52, 293-298, 2000.

Kawate, R., Molchanov, O. A., and Hayakawa, M.: Ultralowfrequency magnetic fields during the Guam earthquake of 8 August 1993 and their interpretation, Phys. Earth Planet. In., 105, 229-238, 1998.

Kopytenko, Y. A., Matishvili, T. G., Voronov, P. M., Kopytenko, E. A., and Molchanov, O. A.: Detection of ultra-low-frequency emissions connected with the Spitak earthquake and its aftershock activity, based on geomagnetic pulsations data at Dusheti and Vardzia observatories, Phys. Earth Planet. In., 77, 85-95, 1993.

Lilley, F. E. M. and Arora, B. R.: The sign convention for quadrature Parkinson arrows in geomagnetic induction studies, Rev. Geophys., 20, 513-518, doi:10.1029/RG020i003p00513, 1982.

Lin, Y. and Zeng, X.: The response of anomalous short period geomagnetic variations to moderate-strong earthquakes in China, Journal of Earthquake Prediction Research, 8, 1-10, 1992.

Liu, J. Y., Chen, C. H., Chen, Y. I., Yen, H. Y., Hattori, K., and Yumoto, K.: Seismo-geomagnetic anomalies and $\mathrm{M} \geqslant 5.0$ earthquakes observed in Taiwan during 1988-2001, Phys. Chem. Earth., 30, 215-222, 2006.

Merzer, M. and Klemperer, S. L.: Modeling low-frequency magnetic-field precursor to the Loma Prieta earthquake with a precursory increase in fulat-zone conductivity, Pure Appl. Geophys., 150, 217-248, 1997.

Molchanov, O. A. and Hsayakawa, M.: Generation of ULF electromagnetic emissions by microfracturing, Geophys. Res. Lett., 22, 3091-3094, 1995.

Molchanov, O. A. and Hayakawa, M.: Seismo Electromagnetics and Related Phenomena: History and latest results, Terra Scientific, Pub. Comp., Tokyo, 189 pp., 2008.

Molchanov, O. A., Kopytenko, Y. A., Voronov, R. M., Kopytenko, E. A., Matiashvili, T. G., Fraser-Smith, A. C., and Bernardi, A.: Results of ULF magnetic field measurements near the epicenters of the Spitak $\left(M_{S}=6.9\right)$ and Loma Prieta $\left(M_{S}=7.1\right)$ earthquakes: Comparative analysis, Geophys. Res. Lett., 19, 14951498, 1992.

Nagata, T.: Anisotropic magnetic susceptibility of rocks under mechanical stresses, Pure Appl. Geophys., 78, 110-122, 1970. 
Ogawa, Y., Yukutake, T., and Utaka, H.: Two-dimensional modeling of resistivity structure beneath the Tohoku district, northern Honshu of Japan, by a finite element method, J. Geomagn. Geoelectr., 38, 45-79, 1986.

Parkinson, W. D.: Directions of rapid geomagnetic fluctuations, Geophys. J. Roy. Astr. S., 2, 1-14, 1959.

Parkinson, W. D.: The influence of continents and oceans on geomagnetic variations, Geophys. J. Roy. Astr. S., 6, 441-449, 1962.

Parkinson, W. D.: Introduction to geomagnetism, Scottish academic press, Edinburgh and London, 433 pp., 1983.

Parkinson, W. D. and Jones, F. W.: The geomagnetic coast effect, Rev. Geophys., 17, 1999-2015, doi:10.1029/RG017i008p01999, 1979.

Simpson, F. and Bahr, K.: Practical magnetotellurics, Cambridge University Press, Cambridge, 270 pp., 2005.

Stacey, F. D.: Theory of the magnetic susceptibility of stressed rocks, Philos. Mag., 7, 551-556, 1962.
Wang, H. L., Zhu, L., and Chen, H. W.: Moho depth variation in Taiwan from teleseismic receiver functions, J. Asian. Earth Sci., 37, 286-291, 2010.

Wen, S., Chen, C.-H., Yen, H.-Y., Yeh, T.-K., Liu, J.-Y., Hattori, K., Peng, H., Wang, C.-H., and Shin, T.-C.: Magnetic storm free ULF analysis in relation with earthquakes in Taiwan, Nat. Hazards Earth Syst. Sci., 12, 1747-1754, doi:10.5194/nhess-121747-2012, 2012.

Yen, H. Y., Chen, C. H., Yeh, Y. H., Liu, J. Y., Lin, C. R., and Tasi, Y. B.: Geomagnetic fluctuations during the 1999 Chi-Chi earthquake in Taiwan, Earth Planets Space, 56, 39-45, 2004.

Yen, H. Y., Chen, C. H., Hsieh, H. H., Lin, C. R., Yeh, Y. H., Tsai, Y. B., Liu, J. Y., Yu, G. K., and Chen, Y. R.: Magnetic Survey of Taiwan and Its Preliminary Interpretations, Terr. Atmos. Ocean. Sci., 20, 309-314, doi:10.3319/TAO.2008.04.08.01(T), 2009.

Zeng, X., Lin, Y., Zhu, Z., Xu, R., Zhao, M., Zhang, C., and Liu, Q.: Study on electric variations of media in epicentral area by geomagnetic transfer functions, Acta Seismologica Sinica, 1, 413418, 1995. 